\title{
The Maryland Amphibian and Reptile Atlas: A Volunteer-Based Distributional Survey
}

\author{
Heather R. Cunningham, ${ }^{1}$ Charles A. Davis, ${ }^{1}$ Christopher W. Swarth, ${ }^{2}$ and Glenn D. Therres ${ }^{3}$ \\ ${ }^{1}$ The Natural History Society of Maryland, P.O. Box 18750, Baltimore, MD 21206, USA \\ ${ }^{2}$ Jug Bay Wetlands Sanctuary, 1361 Wrighton Road, Lothian, MD 20711, USA \\ ${ }^{3}$ Wildlife and Heritage Service, Maryland Department of Natural Resources, 580 Taylor Avenue, Annapolis, MD 21401, USA
}

Correspondence should be addressed to Glenn D. Therres, gtherres@dnr.state.md.us

Received 5 March 2012; Accepted 19 April 2012

Academic Editor: Richard Stafford

Copyright (C) 2012 Heather R. Cunningham et al. This is an open access article distributed under the Creative Commons Attribution License, which permits unrestricted use, distribution, and reproduction in any medium, provided the original work is properly cited.

Declines of amphibian and reptile populations are well documented. Yet a lack of understanding of their distribution may hinder conservation planning for these species. The Maryland Amphibian and Reptile Atlas project (MARA) was launched in 2010. This five-year, citizen science project will document the distribution of the 93 amphibian and reptile species in Maryland. During the 2010 and 2011 field seasons, 488 registered MARA volunteers collected 13,919 occurrence records that document 85 of Maryland's amphibian and reptile species, including 19 frog, 20 salamander, five lizard, 25 snake, and 16 turtle species. Thirteen of these species are of conservation concern in Maryland. The MARA will establish a baseline by which future changes in the distribution of populations of native herpetofauna can be assessed as well as provide information for immediate management actions for rare and threatened species. As a citizen science project it has the added benefit of educating citizens about native amphibian and reptile diversity and its ecological benefits - an important step in creating an informed society that actively participates in the long-term conservation of Maryland's nature heritage.

\section{Introduction}

Amphibian and reptile species are among the most threatened groups of vertebrate animals [1,2]. Factors that lead to population declines are habitat alteration and loss, invasive species, disease, environmental pollution, commercial collection, and climate change $[1,3]$. The lack of thorough understanding of regional distribution patterns of amphibian and reptile populations can limit our ability to predict how species will respond to these factors [4]. An additional challenge to the protection and conservation of amphibian and reptile species (also called herps) is the overall negative perception by the public towards these organisms [5]. There is a pervasive attitude that these organisms are unimportant [5]. However citizen science projects, defined as projects where citizens participate in scientific research [5], have the potential to advance the protection of amphibian and reptile species. Specifically, citizen science-based atlas projects can efficiently assemble distribution information across large spatial scales while increasing environmental awareness in the general public about the ecological importance of herpetofauna. Through participation in atlas projects citizens play an important role in the long-term protection and conservation of amphibians and reptiles.

Currently 93 native species of amphibians and reptiles occur in Maryland (20 anurans, 21 salamanders, 27 snakes, 19 turtles, and six lizards). The diversity of native herpetofauna is, in part, an outcome of the three physiographic provinces in Maryland: Appalachian, Piedmont, and Coastal Plain. Some species are restricted to particular provinces. For example, the Red-bellied Watersnake (Nerodia erythrogaster) and Eastern Tiger Salamander (Ambystoma tigrinum) are restricted to the Coastal Plain, and the Mountain Earthsnake (Virginia valeriae pulchra) and Green Salamander (Aneides aeneus) are found exclusively in the Appalachian Province. In 1975 Harris Jr., [6] compiled the most recent set of comprehensive maps for Maryland herpetofauna. 
That publication maps the historic distribution of reptile and amphibian species in Maryland from the early 1900s through the mid 1970s using sightings and locality records of specimens collected and held in private collections, universities, museums, and with the Natural History Society of Maryland [7].

Since the Harris publication [6], Maryland has become much more urbanized, and natural lands have diminished. Additionally, land management practices, animal disease distribution, water pollution abatement practices, or climate have altered habitat suitability and population fitness of Maryland's herpetofauna. For example, researchers in Maryland found that particular timber management practices, specifically cutting and burning of small patches of forest can result in decreased local diversity of herpetofauna [8]. The amphibian chytrid fungus, Batrachochytrium dendrobatidis, which is responsible for the disease chytridiomycosis, now occurs in the Chesapeake and Ohio Canal National Historic Park, where researchers documented this pathogen in two species of stream-associated salamanders [9]. Changes to climate will inherently alter the hydrologic cycle [10]—a direct concern to habitat quality of regional herpetofauna. Further, Maryland researchers observed that in urban environments amphibians are attracted to stormwater retention ponds where they become exposed to trace metal contamination from accumulated runoff [11]. In addition to changing environmental conditions, relative to other states in the United States, Maryland ranks in the top 25th percentile for number of native amphibian and reptile species at risk of extinction [12]. Maryland has 11 species of reptiles and eight amphibians that have state conservation status of endangered, threatened, or in-need-of-conservation [13]. All of these factors reinforce the critical need to understand the current distribution patterns of amphibian and reptile species within the state.

Ecological atlases are one of the many types of citizen science projects that have been successfully conducted throughout the world [14]. Atlases show the distributions of organisms such as birds, butterflies, or plants for a given geographic area. Specifically, they are presence-only data sets of spatially explicit species occurrence data [15]. Most atlases use a predefined grid for sampling, employ a sampling protocol, have minimum requirements for the submission of data [16], and rely on citizen scientists to collect the data. The experience level of atlas volunteers can range from amateurs, with little scientific training, to scientists who specialize in the species of interest.

Atlas projects ultimately produce maps of the distribution of focal species. Repeated atlas efforts and comparisons can detect species' distributional shifts. Atlas data can inform scientists about these shifts and provide important information for focused studies on the causes. The first ecological atlas using a systematic approach to collecting field data was conducted in the United Kingdom for plants $[17,18]$. In North America, many breeding bird atlases have been conducted in accordance with guidance provided by the North American Breeding Bird Atlas Committee [19] and subsequently published. Additionally, atlases for reptiles and amphibians have been completed or are in progress in several states in North America (see review [4]). In recent years, the methodology for citizen involvement and data collection for atlas projects has evolved with advances in new technology (e.g., the internet, social media, and digital photography). Current projects use the internet extensively as a means to gather and distribute information [4].

The Maryland Amphibian and Reptile Atlas project (MARA) is a citizen science project with the goal to document the current distribution of all amphibian and reptile species in Maryland using a systematic and repeatable approach during the five-year period, 2010-2014. Another important goal is to provide current information on the location and status of rare or threatened species. MARA data will inform management strategies for the immediate and longterm conservation and protection of Maryland's herpetofauna. Surveying large areas, such as an entire state, requires significant volunteer assistance and provides an opportunity to recruit and train novice participants, and thereby raises general ecological literacy by increasing awareness, skills, understanding, and knowledge of the natural world.

The Maryland Department of Natural Resources (MDNR) and the Natural History Society of Maryland (NHSM) cosponsor the project. The MDNR is the chief government agency responsible for conservation of the herpetofauna of the state. The NHSM, established in 1929, supports the community of amateur and professional naturalists within the state and during the intervening years has organized and published research on Maryland herpetology.

\section{Approach}

Conducting the atlas project entails four principal challenges: defining the survey methods, preparing data handling strategies, recruiting volunteers, and managing the volunteer network. The methodological foundation for MARA is based on herpetofauna atlases conducted in other states and two Maryland breeding bird atlases: 1983-1987 and 2002-2006 [4, 20-22]. Volunteer recruitment and management today can take advantage of online social networking to establish and maintain the research community for the project. We are implementing the atlas project by using these strategies.

2.1. The Atlas Survey Grid. Building an atlas on a grid base helps to meet the objective of using a systematic and repeatable method. The MARA uses a grid based on US Geological Survey 7.5-minute topographic quadrangle maps (called quads) divided into six equal blocks (Figure 1). The blocks are designated as northeast, northwest, central east, central west, southeast, and southwest. Each atlas block covers approximately $25 \mathrm{~km}^{2}$. The state of Maryland includes 1,300 of these blocks within all or portions of 260 quads. This is the same grid system that was used successfully in the two previous breeding bird atlases conducted in Maryland $[20,21]$.

2.2. Search Effort Targets. In 2009, prior to initiating the MARA project, a pilot study was conducted in one Maryland 


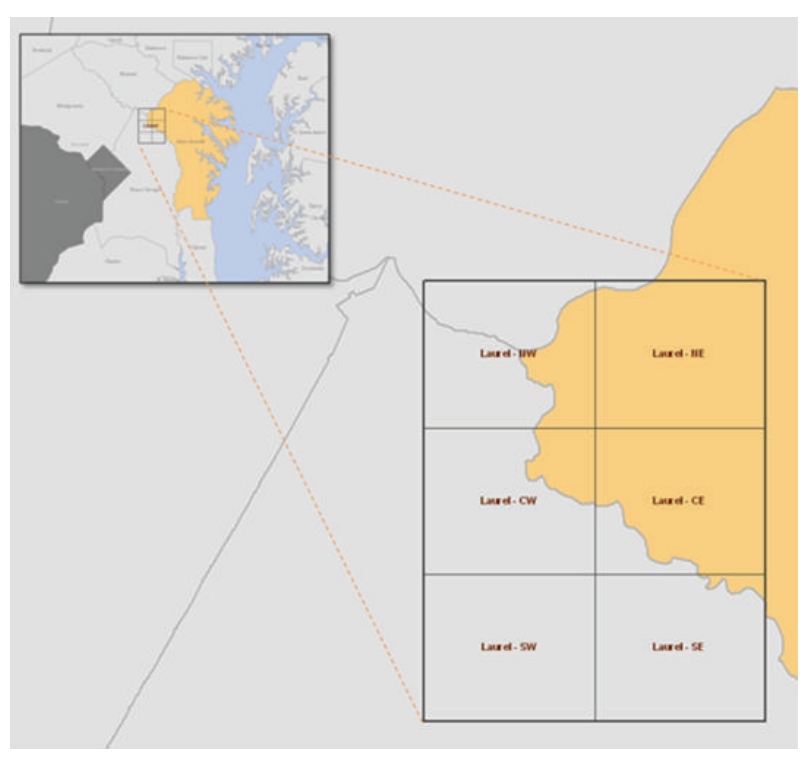

FIgure 1: Example of a US Geological Survey 7.5-minute topographic quadrangle map divided into six atlas blocks.

county to develop the procedures and goals [23]. The pilot study helped to determine possible discovery rates of organisms per unit of survey effort. Providing an estimate of search effort is one way of standardizing results, assuming that the relationship between sampling effort and sample size is consistent [16]. In an earlier Maryland study, researchers documented that time-area searches were as or more effective than intensive trapping methods for documenting herpetofaunal presence [24]. To help assure dispersed geographic coverage across the state, the MARA Steering Committee established two goals for adequate coverage based on number of species discovered (at least ten species per atlas block and 25 species per quad) and the amount of time spent actively searching (at least 25 hours of active searching within each quad). Once these thresholds are reached in a block or quad, then surveyors should move to another less thoroughly searched area. In some blocks, which are highly urbanized, or dominated by one habitat type (i.e., Chesapeake Bay), reaching the ten species threshold may not be possible. In those instances, once the quad thresholds are met, surveyors are encouraged to move to a new quad. Cumulative time spent searching in a particular block is captured within the database as a record of effort for future comparisons. These guidelines balance the probable species numbers to be detected with the expected volunteer capacity to search the state within the project interval.

2.3. Time Period of Survey. Deciding the interval of the survey is strictly an estimate of the time to complete the effort based on the expected recruitment and effort of volunteers, as well as the anticipated detection rate of the herps. Ideally, this is the narrowest time interval possible so that the results will be least affected by any changes in distribution that may happen during the survey period. We chose a five-year period based on assessments of other state herpetological atlases (e.g., for Maine [25]), experiences from the pilot study, and experience with five-year survey periods used during the two Maryland bird atlases [20, 21].

2.4. Acquiring the Data. Data collected during active searching or incidental observations are recorded on a standard data sheet. Among the information recorded on the data sheet is locality and observer information; additionally the data sheet contains a checklist of all native species in the state by common names based on Crother et al. [26]. Surveyors complete one data sheet per year for each atlas block surveyed. Herpetological occurrence records are obtained by fundamentally two approaches: "active searching" or "incidental observations." Active searching is the main source of atlas data and involves intentional looking for reptiles and amphibians. There are no standardized methods used during active searching. Data are collected through listening surveys for calling frogs and toads, searching various habitats, turning over logs and cover boards, scanning ponds for turtles, turning over rocks along streams, and so forth.

We measure active searching by recording the amount of time a surveyor conducts searches in a given atlas block on each date of survey work. Incidental observations are sightings that observers make when they are not engaged in a formal, active searching survey. Incidental records are added to the database just as active searches, except no survey time is noted.

2.5. Additional Identity Verification Information. For most common species, no additional information is required although photographs for each occurrence record are encouraged similar to procedures of the Carolina Herp Atlas [4]. However, verification is required for certain species and surveyors complete an additional data form for those observations. Verification is required for rare species to obtain exact location information or for difficult-to-identify species so that we can be certain that identifications are accurate and correct. For example, photographic or written verification is required for Common Five-lined Skink (Plestiodon fasciatus) and Broad-headed Skink (P. laticeps) which are closelyrelated species and require close inspection of head scales to differentiate them. Similarly, the two species of gray treefrogs (Hyla versicolor and $H$. chrysoscelis) require vocal recordings because these identical species can only be distinguished by their calls. Verification is required for all records of eggs or larvae of any species. Photodocumentation is the main practice to verify species identity, but written documentation can be considered. In addition to those species for which verification is required, we encourage photodocumentation of each species found within a quad. Employing verification reduces misidentification of species, a serious error that can occur in citizen scientist projects [16].

2.6. Verification Committee. All photos, audio recordings of anuran calls, and verification forms are reviewed by a verification committee who are experienced with Maryland's herpetofauna (Figure 2). Photos and audio recordings are 


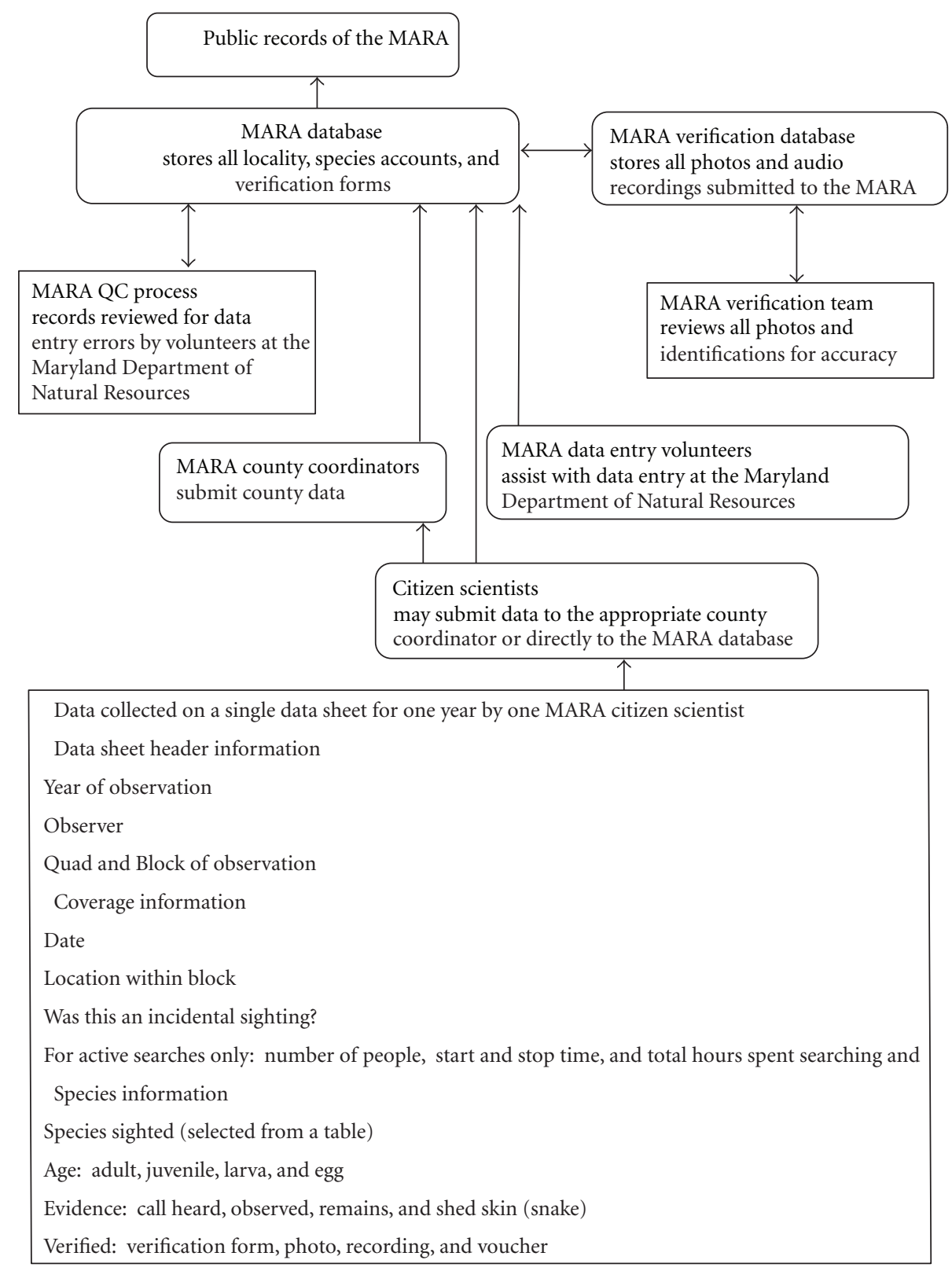

Figure 2: Data recorded and flow through the Maryland Amphibian and Reptile Atlas from collection to public release.

reviewed independently by each member of the committee via an online system. Only the photo or sound recording is provided to the reviewer with no additional information (no species name or observer name), except the county of occurrence. If the first three committee members to vote agree on the species identity, the record is confirmed; otherwise, the record is placed in a process to resolve the disputed record. Records are labeled "confirmed," if sufficient evidence was provided to the verification committee; "accepted" if no verification was required; or "unconfirmed" if the species required verification but none was provided or the verification committee could not positively determine the species' identity.
2.7. Database. Data are managed through a central MARA database, which was developed and maintained by the MDNR (https://webapps02.dnr.state.md.us/mara/default .aspx). Surveyors can enter data and submit verification photographs through online access to the database (Figure 2). County coordinators can access summary statistics here, view additional data summaries, and grant access for surveyors. Similarly, the verification committee accomplishes their duties through an associated portal to the submitted photographs. The central database is updated regularly with the decisions of the verification committee. Summary tables of the data are available on line to the volunteers, county coordinators, steering 


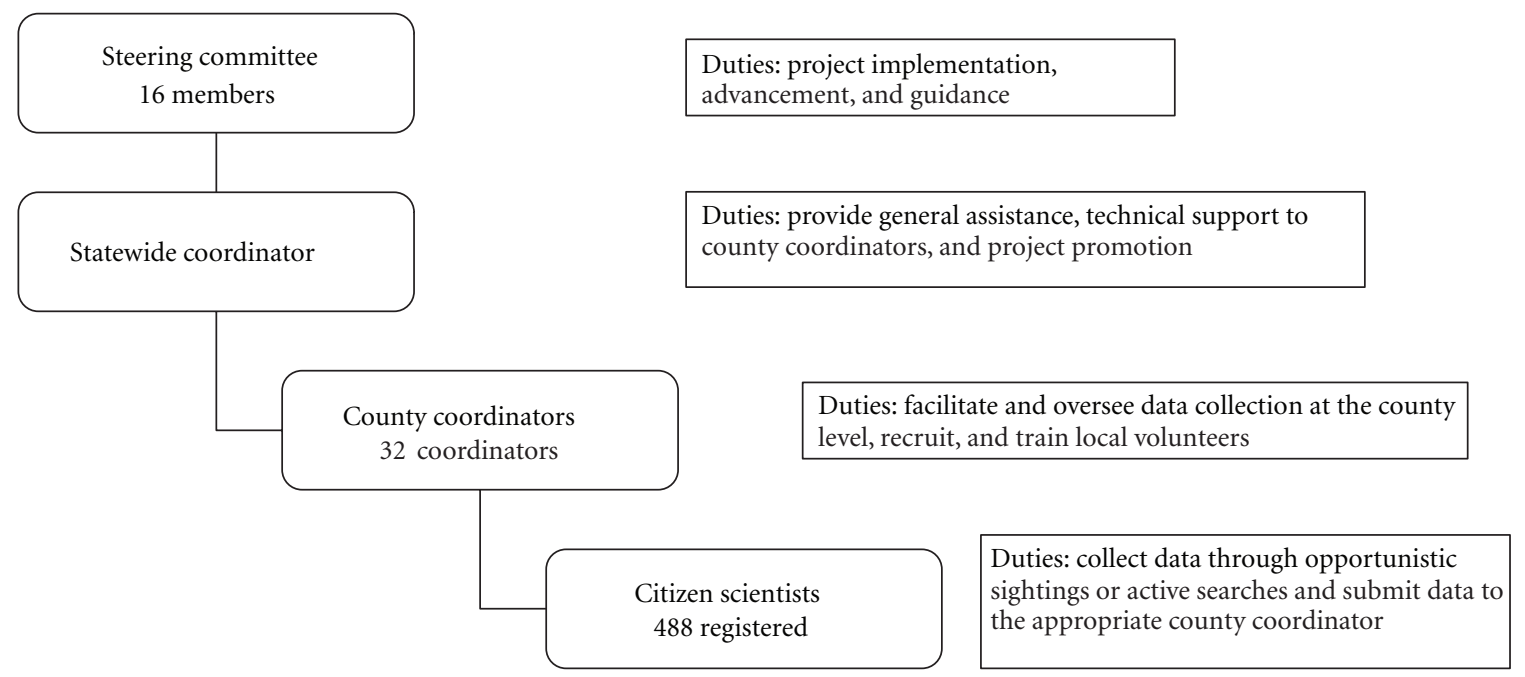

FIgURE 3: Organizational structure of the Maryland Amphibian and Reptile Atlas project.

committee members, and the public. This real-time data helps volunteers and coordinators plan for the field season and check on previous records. Allowing volunteers to examine the collected data is an important educational aspect of citizen science [27]. The MARA database will be used to produce distribution maps for all the reptile and amphibian species documented during the atlas project.

2.8. State Project Steering Committee. Recruiting, organizing, and mobilizing volunteers to achieve the project goals and objectives required oversight at statewide and local levels (Figure 3). Oversight of the MARA project is guided by a steering committee of 16 members. Successful citizen science projects require a development team comprising multiple partners and disciplines [27]. Three members cochair the steering committee, including representatives of the two primary project sponsors. The initial function of the steering committee was to develop the protocols of the distributional survey and recruit volunteer coordinators. As the atlas project got underway, the role of the steering committee shifted to project implementation and resolving technical issues. The steering committee meets monthly.

2.9. State Project Coordinator. To assist the county coordinators with recruiting, training, and motivating volunteers, and to develop strategies for collecting field data, a statewide coordinator was hired in August 2010. The statewide coordinator also conducts outreach efforts to promote the project, and to recruit and train additional volunteers. Additionally, the statewide coordinator produces a monthly project newsletter, educational materials relevant to the MARA project, and maintains the MARA website and social networking site. Federal wildlife grant money provided to the MDNR has been used to fund the statewide coordinator through a contract with the NHSM.
2.10. County Coordinators. Maryland contains 23 counties, and the MARA project chose to organize field data collection at this level. The county coordinators are integral to the success of the statewide effort. Coordinators work at the local level to recruit volunteers and to oversee the collection of field data within their counties. One to two coordinators were recruited for each county.

The county coordinators employ various strategies to achieve adequate coverage within their counties. They all recruit and coordinate volunteers to collect field data. A few counties are coordinated by employees of county park and recreation agencies that have access to networks of volunteers interested in reptiles and amphibians. These coordinators rely heavily on that network to obtain data. Other coordinators rely on a few dedicated volunteers to collect most of the field data within their county.

For the county coordinators, an annual meeting has been held each February beginning in 2010 to prepare for the upcoming field season. Topics of discussion at these meetings include how to recruit volunteers, strategies for achieving adequate coverage of blocks and quads, field techniques for finding reptiles and amphibians, and success stories presented by some of the county coordinators themselves. This meeting is an important annual check on progress of the project and a rally for the upcoming field season.

2.11. Recruiting Volunteers. Volunteers were recruited to the MARA project using various methods. Articles describing the MARA project and the need for volunteers were published in newspapers and nature club newsletters. Volunteers were also recruited at wildlife and nature festivals hosted at nature centers. MARA information was displayed before organizations such as the Maryland Association of Environmental and Outdoor Education in 2011 and 2012. Additionally, the two previous Maryland breeding bird atlases provided an existing network of citizen scientists experienced 
in atlas methods from which to recruit volunteers for the MARA through appeals at the Maryland Ornithological Society annual conferences in 2011 and 2012 and articles in their newsletter. Volunteers are also recruited through Facebook and Volunteer Match (http://www.volunteermatch.org/).

2.12. Training Volunteers. To aid the volunteers, several resources were developed to explain data collection and to ensure that data are assigned to the proper atlas block and quad. A handbook [28] was developed and provided to volunteers. The handbook explains the purpose of the project, grid system, data forms, techniques for finding reptiles and amphibians, and recommended references for species identification. The handbook also discusses health and safety precautions that are relevant to amphibian and reptile surveys. Measures for protecting habitat, animals, and surveyors are discussed in the handbook, covered at MARA training sessions and in the monthly project newsletter.

Paper copies of atlas blocks and a digital overlay of the grid system for use with Google Earth were made available to the volunteers. These and other resources are available on the project website (http://marylandnature.org/mara/) to guide data collection. In addition, county coordinators frequently held training sessions at the beginning of each field season to offer hands-on or technical training to volunteers. In some counties, coordinators held public hikes during which volunteers gained practical training while actively surveying for amphibians and reptiles.

2.13. Retaining Volunteers. As a means of retaining volunteers, two outreach products were developed. A monthly newsletter was initiated in November 2010. The newsletter encourages submissions from MARA participants. Photographs of interesting amphibian and reptile species encountered are highlighted in the newsletter in addition to accounts of experiences of MARA volunteers in the field. When county coordinators receive the newsletter by email, they send it to their local volunteers, and the newsletters are available to the general public through the project website. We established a Facebook page (https://www.facebook.com/MDHerpAtlas) in October 2011 to provide a forum for online exchange of project information and to encourage volunteers to communicate with each other. Volunteers are invited to post photographs and amphibian and reptile sighting information on the Facebook page.

\section{Preliminary Results}

3.1. Volunteer Recruitment. From January 1, 2010 to February 22, 2012, 488 citizen scientists have registered with the MARA database and contributed observations. This is a conservative estimate of the total number of actual contributors to the MARA, since this includes neither landowners that have granted access to private property nor those who assisted registered volunteers with active searching.

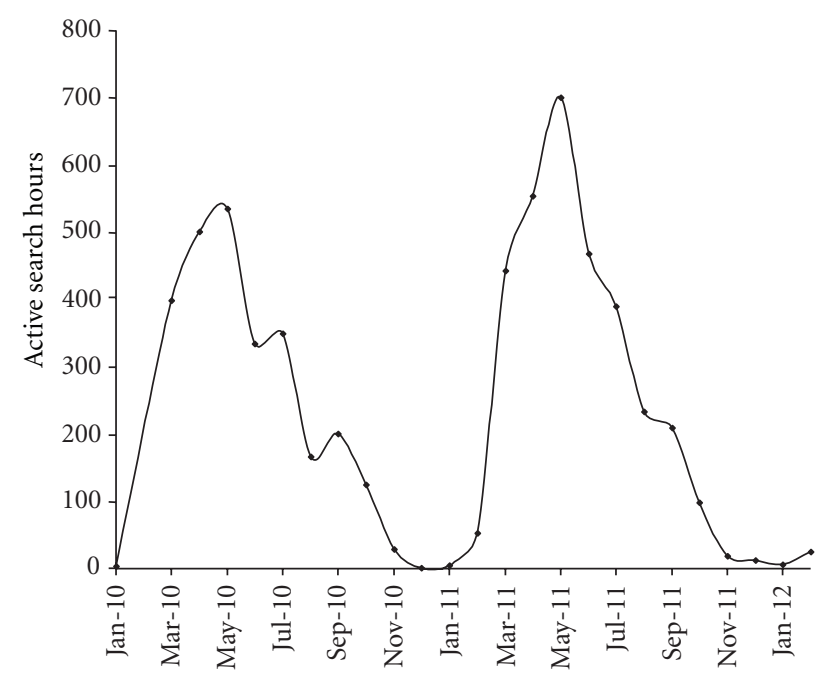

FIgure 4: Survey hours for the Maryland Amphibian and Reptile Atlas.

3.2. Observation Counts. Surveyors have reported 13,919 occurrence records. This total includes 457 records from one county that were generated during the 2009 pilot study [23]. The mean number of occurrence records submitted per volunteer was $28.52 \pm 106.13$ (mean \pm standard deviation, SD) with about $21 \%(5.89 \pm 20.72)$ of the records being incidental observations (Table 1). Some observers contribute many more sightings than others. For instance, three observers submitted over 1,000 records each, five submitted between 500 and 1,000 each, and 39 submitted between 50 and 500 records. Sixty-nine percent of the volunteers submitted fewer than ten records each, and of those volunteers 186 submitted just one observation. Eighty percent of the records were contributed by $10 \%$ of the surveyors.

3.3. Time Effort Progress. Fifty-two percent (128/246) of quads have reached the minimum coverage goals of 25 species or 25 survey hours. Registered and unregistered volunteers have reported a total of 12,671 survey hours, but the number of survey hours reported per quad and block varied (Table 2). For instance, the total number of hours spent actively searching by all surveyors in particular quads ranged from 0 to 649 hours. The mean number of survey hours, or active searching hours, per registered participant was $12.48 \pm 42.80$ hours (Table 1 ). Survey effort occurred primarily throughout the spring and summer months, although records have been reported from every month of the year (Figure 4).

3.4. Areal Coverage Progress. Surveyors have collected data from 232 quads and 1,302 blocks (Figure 5). Thirty percent $(74 / 246)$ of the quads have reached the minimum coverage goal of 25 species. Overall, surveyors observed $20.43 \pm 10.44$ and $8.27 \pm 7.82$ species per quad and block, respectively (Table 2$)$. Forty-one percent $(542 / 1,302)$ of the blocks have reached the minimum coverage goal of 10 species. On 
TABLE 1: Number of occurrence records and search effort of registered MARA volunteers.

\begin{tabular}{|c|c|c|c|c|c|c|}
\hline Volunteer contribution & Mean (per volunteer) & Mode & Frequency of mode & Minimum & Maximum & SD \\
\hline Records submitted & 28.52 & 1 & 186 & 0.00 & 1069.00 & 106.13 \\
\hline Opportunistic records & 5.89 & 1 & 224 & 0.00 & 280.00 & 20.72 \\
\hline Active search hours & 12.49 & 0 & 302 & 0.00 & 389.75 & 42.80 \\
\hline Quads surveyed & 2.98 & 1 & 334 & 1.00 & 82.00 & 6.92 \\
\hline Blocks surveyed & 5.53 & 1 & 316 & 1.00 & 284.00 & 18.76 \\
\hline
\end{tabular}

TABLE 2: Species observed and person-hours of effort for blocks and quads.

\begin{tabular}{lcccc}
\hline Assessment & Count (quads/blocks) & Mean & Minimum & Maximum \\
\hline Species reported per quad & 232 & 20.34 & 1 & 48.00 \\
Species reported per block & 1301 & 8.27 & 0 & 43.00 \\
Person-hours per quad & 246 & 51.51 & 0 & 7.82 \\
Person-hours per block & 1301 & 9.74 & 0 & 79.54 \\
\hline
\end{tabular}

TABLE 3: Mean number of presence records per class/order per quad. Number of quads $=232$.

\begin{tabular}{lcc}
\hline Class/order & Mean & SD \\
\hline Amphibia/Anura & 27.43 & 26.03 \\
Amphibia/Caudata & 6.59 & 8.35 \\
Reptilia/Squamata-Lacertilia & 1.73 & 3.65 \\
Reptilia/Squamata-Serpentes & 12.62 & 13.70 \\
Reptilia/Testudines & 11.42 & 11.37 \\
\hline
\end{tabular}

average, each registered participant collected data in 2.98 \pm 6.92 quads and $5.53 \pm 18.76$ blocks (Table 1 ).

3.5. Species Detection Progress. Eighty-five of Maryland's 93 native amphibian and reptile species have at least one occurrence record in the MARA database. Distributional data have been recorded for 19 frog, 20 salamander, five lizard, 25 snake, and 16 turtle species. Volunteers also located 12 nonnative amphibian and reptile species. Anuran records comprise $45 \%(6,371 / 13,919)$ of the records in the database (Figure 6). The mean number of anuran records in surveyed quads was $27.43 \pm 26.03$ (Table 3 ). The second most commonly sighted group per quad was snakes, with salamanders and lizards sighted less frequently per quad. The most commonly reported species, per taxonomic order, were Spring Peeper (Pseudacris crucifer; 946 records), Redbacked Salamander (Plethodon cinereus; 431 records), Common Five-lined Skink (Plestiodon fasciatus; 212 records), Eastern Ratsnake (Pantherophis alleghaniensis; 617 records), and Eastern Box Turtle (Terrapene carolina; 665 records; Figure 3). Several records have also been collected on species listed as threatened or endangered in Maryland (Table 4). For example, volunteers submitted occurrence records for the state endangered Mountain Earthsnake (Virginia valeriae pulchra) from two previously undocumented locations. In addition, volunteers submitted two records for the state endangered Rainbow Snake (Farancia erytrogramma).

Voucher photographs or audio recordings accompanied $37 \%(5,203)$ of the submitted records. Through February 22,
2012, the verification committee has reviewed 4,406 records and determined that only $4 \%$ of the submitted records were misidentified.

\section{Discussion}

Public participation in the MARA resulted in a total of 13,919 occurrence records, in just 25 months. The MARA compares well with other successful herpetofauna atlases including the Georgia Herp Atlas [29] which collected 7,452 records during five years and the Carolina Herp Atlas [4] (currently underway) which collected 11,663 records during its first 36 months.

Though the number of registered participants was nearly 500 through the first two years of the MARA project, the majority of species records were submitted by less than $10 \%$ of the volunteers. This is consistent with the Carolina Herp Atlas [4]. However, the value of the few records submitted by the majority of the volunteers is also important. Their discoveries included difficult to find species, including salamanders and small snakes, and most of the nonnative species. Typically, volunteers participate in citizen scientist projects because they enjoy being able to put their skills to use in searching for and identifying species of the target group [16]. However, finding enough of these volunteers throughout the project area is the challenge in any widespread atlas effort.

The MARA project currently has a solid volunteer corps who freely contribute to the project by serving as county coordinators, steering committee members, and field workers. However, retaining volunteers for the duration of the project requires regular communication between the project management team and data collectors. This is important to ensure success of the project. Regular updates on progress are communicated via the project website, monthly electronic newsletter, and a social networking website. This communication is vital to ensure the participants remain interested and feel that the data being collected are being used [16]. The monthly newsletter and social networking site 

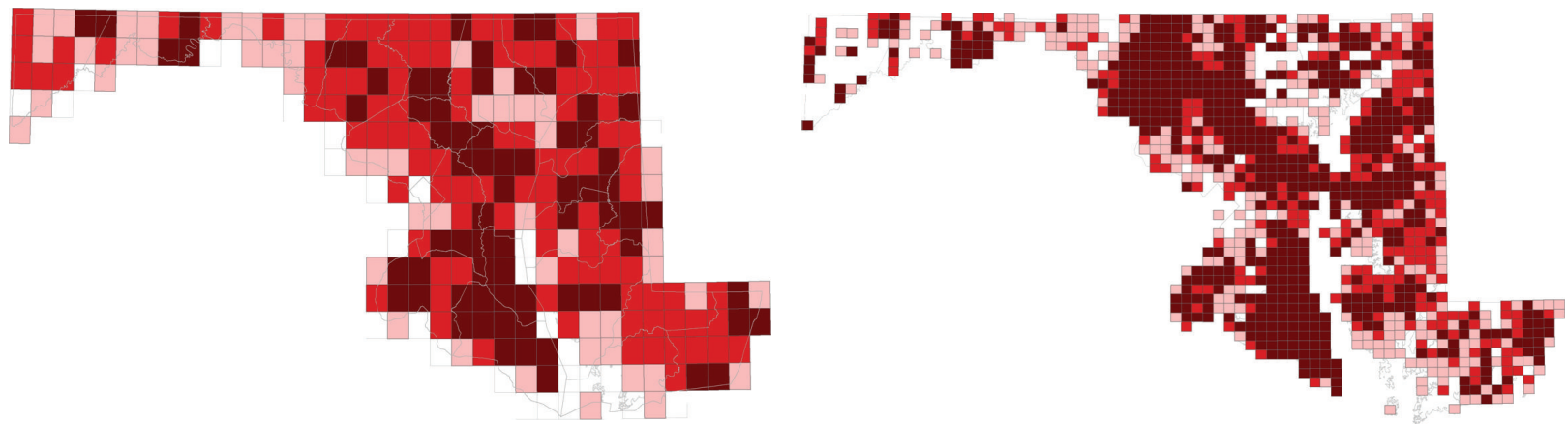

Number of species

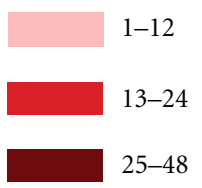

Number of species

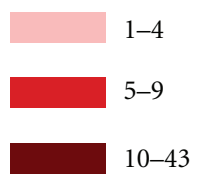

(a)

(b)

Figure 5: Results of the Maryland Amphibian and Reptile Atlas as of February 20, 2012. The number of species recorded in each quad (a) and block (b) is shown in a categorized series.

TABLE 4: Number of occurrence records of amphibian and reptile species submitted to the MARA that the state of Maryland lists as endangered (E) or threatened (T).

\begin{tabular}{|c|c|c|c|}
\hline Class/order & Species & State status & Number of records \\
\hline \multirow{2}{*}{ Amphibia/Anura } & Barking Treefrog (Hyla gratiosa) & $\mathrm{E}$ & 2 \\
\hline & Eastern Narrow-mouthed Toad (Gastrophryne carolinensis) & $\mathrm{E}$ & 1 \\
\hline \multirow{3}{*}{ Amphibia/Caudata } & Eastern Hellbender (Cryptobranchus alleganiensis) & $\mathrm{E}$ & 1 \\
\hline & Eastern Tiger Salamander (Ambystoma maculatum) & $\mathrm{E}$ & 5 \\
\hline & Green Salamander (Aneides aeneus) & $\mathrm{E}$ & 5 \\
\hline \multirow{2}{*}{ Reptilia/Squamata-Serpentes } & Mountain Earthsnake (Virginia valeriae pulchra) & $\mathrm{E}$ & 3 \\
\hline & Rainbow Snake (Farancia erytrogramma) & $\mathrm{E}$ & 2 \\
\hline \multirow{6}{*}{ Reptilia/Testudines } & Bog Turtle (Glyptemys muhlenbergii) & $\mathrm{T}$ & 27 \\
\hline & Green Sea Turtle (Chelonia mydas) & $\mathrm{T}$ & 1 \\
\hline & Kemp Ridley Sea Turtle (Lepidochelys kempii) & $\mathrm{E}$ & 5 \\
\hline & Leatherback Sea Turtle (Dermochelys coriacea) & $\mathrm{E}$ & 1 \\
\hline & Loggerhead Sea Turtle (Caretta caretta) & $\mathrm{T}$ & 14 \\
\hline & Northern Map Turtle (Graptemys geographica) & $\mathrm{E}$ & 3 \\
\hline
\end{tabular}

have been valuable tools to retain volunteers and increase communication among them.

To achieve consistent coverage, many atlas programs have standard benchmarks based on the number of species sampled within a given block or the hours of effort [14]. The MARA has set minimum coverage goals of 25 species or 25 survey hours per quad and 10 species per block. Currently, the MARA is on course to achieve these goals statewide by the end of 2014. We have achieved the minimum coverage goal of 25 active search hours within 52\% of quads and the coverage goal of at least 10 species per block in $41 \%$ of blocks. With repeated atlases, often spanning twenty years or more, effort and the change in effort for individual blocks are crucial sources of variation that should be accounted for. When programs have no requirement for minimum effort, studies may be biased, resulting in overreporting of rare species, underreporting of common species, and failure to report repeated sightings because they are not deemed as interesting by the observer [14]. Further, people may simply stop sampling when there are no interesting organisms to be seen.

Atlasing efforts play an important role in biodiversity conservation by providing essential data on the occurrence of species [16]. The majority of records are anuran, most likely because anurans can be detected by sight and sound. To date, salamander and lizard records are not well represented in the MARA. The cryptic nature of salamanders and strict seasonal activity patterns of particular species (e.g., ambystomid species) likely contribute to the low number of salamander records. Of the six lizard species occurring within 


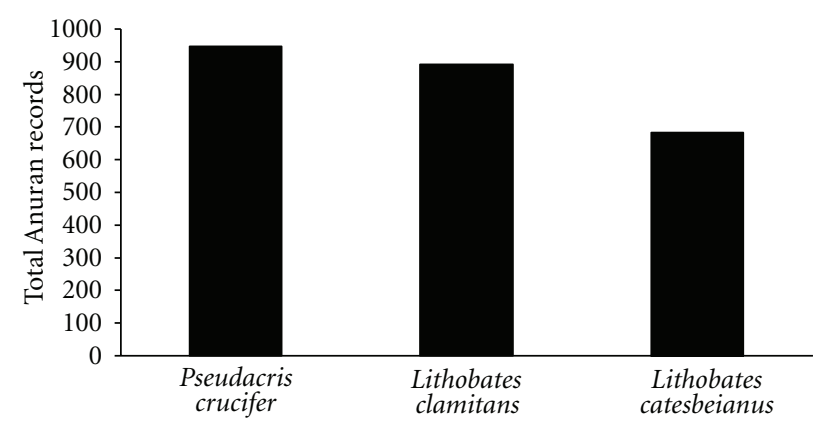

(a)

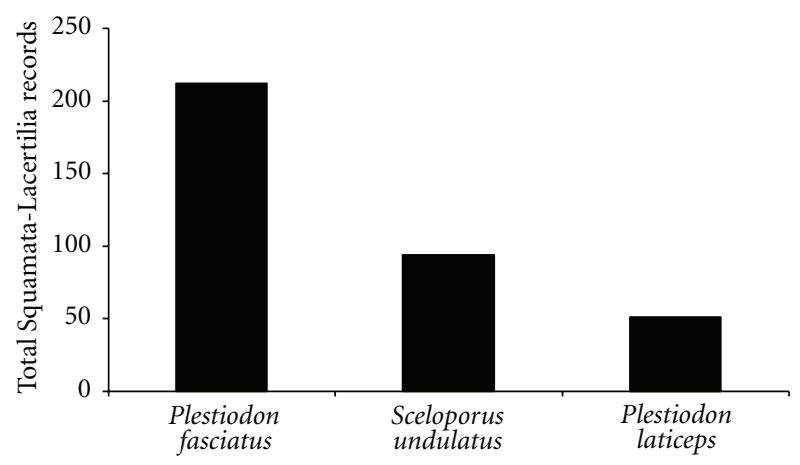

(c)

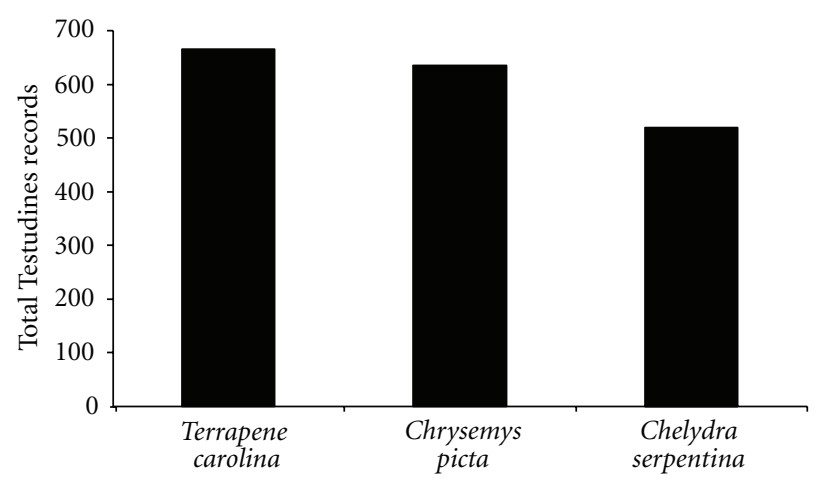

(e)

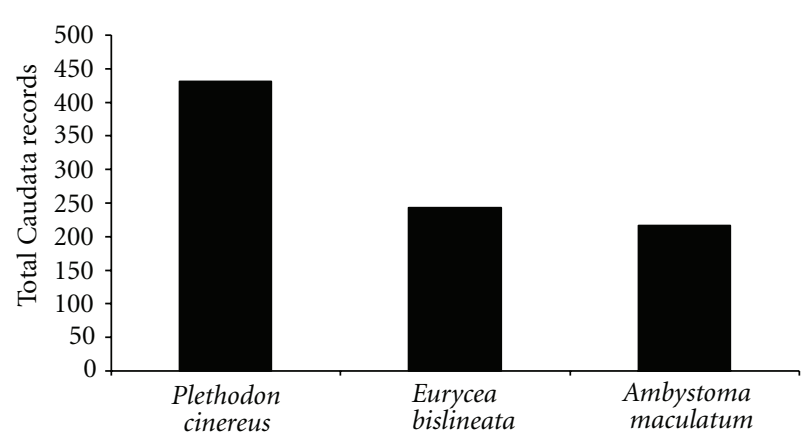

(b)

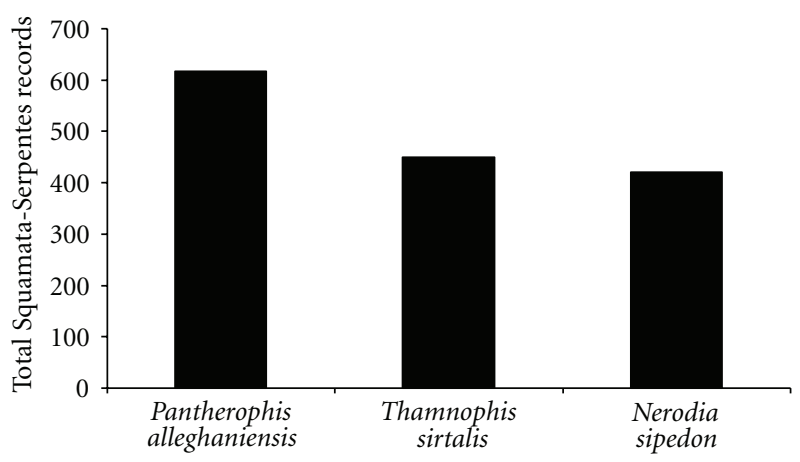

(d)

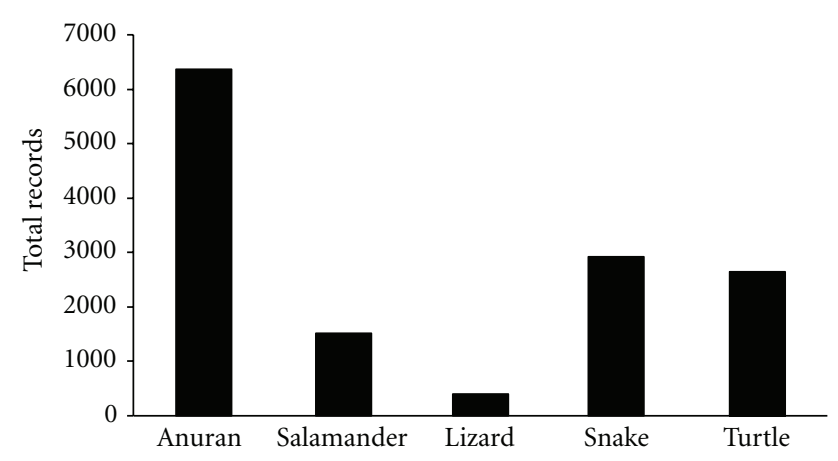

(f)

Figure 6: The most commonly reported species of frog (a), salamander (b), lizard (c), snake (d), turtle (e), and total number of records per group (f) through February 22, 2012.

Maryland, several have very restricted ranges which may explain the paucity of records. Several strategies have been helpful to increase records for these species. The availability of real-time data through the MARA database has allowed participants to be informed of the disparity in the record counts for the different groups. Information on how to survey for the underrepresented groups was shared with participants, resulting in an increase in record counts for those groups from 2010 to 2011.

Ultimately, the usefulness of atlas projects depends on the quality and quantity of data collected as well as the standardization of sampling methods and the appropriateness of the scale of sampling for the research question. An important function of our verification process is its capacity to quantify and correct error rates. The verification committee detected two primary error types during the early phase of the project: (1) animals were misidentified prior to data submission and (2) errors when submitting data to the online database, such as wrong photos submitted with a record or wrong species identity selected during data entry. The verification procedure enabled these errors to be identified and corrected prior to the records being finalized and the communication systems in place allowed feedback to the citizen scientists to reduce further errors. For example, in response to these findings, the MARA newsletter included, over the course of several months, articles containing information and techniques to identify the species that were found to be frequently misidentified and others discussing database usage and data entry. 
Citizen science is perhaps the only practical way to achieve the geographic reach required to document ecological patterns and address ecological questions at scales relevant to species range shifts, broad-scale population trends, and impacts of environmental processes like landscape and climate change [14].

The MARA will establish a baseline by which future changes in the distribution of populations of native herpetofauna can be assessed. This project will be used to inform long-term conservation and protection strategies for Maryland's amphibian and reptile species. The MARA provides an opportunity for citizens to actively learn about native species while collecting valuable distributional data that the Natural History Society of Maryland and the Maryland Department of Natural Resources will use for the conservation and protection of Maryland's amphibians and reptiles. Educating citizens about native amphibian and reptile diversity and its ecological benefits is an important step in creating an informed society that actively participates in the long-term conservation and protection of Maryland's natural heritage.

\section{Acknowledgments}

The MARA is funded in part by State Wildlife Grant funds provided to the state wildlife agencies by US Congress and administered through the Maryland Department of Natural Resources' Wildlife and Heritage Service. Thanks go to all the MARA county coordinators, steering committee members, verification committee members, and volunteers who generously gave their time to the project. The authors extend gratitude to all the private landowners and public land managers who granted land access for surveys. Thanks are extended to Lynn Davidson and Bob Swan for developing the MARA database.

\section{References}

[1] J. W. Gibbons, D. E. Scott, T. J. Ryan et al., "The global decline of reptiles, deja vu amphibians," BioScience, vol. 50, no. 8, pp. 653-666, 2000.

[2] S. N. Stuart, J. S. Chanson, N. A. Cox et al., "Status and trends of amphibian declines and extinctions worldwide," Science, vol. 306, no. 5702, pp. 1783-1786, 2004.

[3] J. P. Collins and A. Storfer, "Global amphibian declines: sorting the hypotheses," Diversity and Distributions, vol. 9, no. 2, pp. 89-98, 2003.

[4] S. J. Price and M. E. Dorcas, "The Carolina Herp Atlas: an online, citizen-science approach to document amphibian and reptile occurrences," Herpetological Conservation and Biology, vol. 6, no. 2, pp. 287-296, 2011.

[5] J. W. Gibbons, "The management of amphibians, reptiles, and small mammals in North America: the need for an environmental attitude adjustment," in Management of Amphibians, Reptiles, and Mammals in North America, R. C. Szaro, Ed., USDA Forest Service General Technical Report RM-166, pp. 4-10, Rocky Mountain Forest Range Experiment Station, Fort Collins, Colo, USA, 1988.

[6] H. S. Harris Jr., "Distributional survey (Amphibia/Reptilia): Maryland and the District of Columbia," Bulletin of the
Maryland Herpetological Society, vol. 11, no. 3, pp. 73-167, 1975.

[7] H. S. Harris Jr., "The past history of documenting the distribution of amphibians and reptiles of Maryland and the District of Columbia," Bulletin of the Maryland Herpetological Society, vol. 45, no. 1, pp. 14-16, 2009.

[8] R. F. McLeod and J. E. Gates, "Response of herpetofaunal communities to forest cutting and burning at Chesapeake Farms, Maryland," American Midland Naturalist, vol. 139, no. 1, pp. 164-177, 1998.

[9] E. H. Campbell Grant, L. L. Bailey, J. L. Ware, and K. L. Duncan, "Prevalence of the amphibian pathogen Batrachochytrium dendrobatidis in stream and wetland amphibians in Maryland, USA," Applied Herpetology, vol. 5, no. 3, pp. 233-241, 2008.

[10] R. T. Brooks, "Potential impacts of global climate change on the hydrology and ecology of ephemeral freshwater systems of the forests of the northeastern United States," Climatic Change, vol. 95, no. 3-4, pp. 469-483, 2009.

[11] R. E. Casey, A. N. Shaw, L. R. Massal, and J. W. Snodgrass, "Multimedia evaluation of trace metal distribution within stormwater retention ponds in suburban Maryland, USA," Bulletin of Environmental Contamination and Toxicology, vol. 74, no. 2, pp. 273-280, 2005.

[12] B. A. Stein, States of the Union: Ranking America's Biodiversity, NatureServe, Arlington, Va, USA, 2002.

[13] Maryland Natural Heritage Program, Rare, Threatened and Endangered Animals of Maryland, Maryland Department of Natural Resources, Wildlife and Heritage Service, Annapolis, Md, USA, 2010.

[14] J. L. Dickinson, B. Zuckerberg, and D. N. Bonter, "Citizen science as an ecological research tool: challenges and benefits," Annual Review of Ecology, Evolution, and Systematics, vol. 41, pp. 149-172, 2010.

[15] A. M. Dunn and M. A. Weston, "A review of terrestrial bird atlases of the world and their application," Emu, vol. 108, no. 1, pp. 42-67, 2008.

[16] M. P. Robertson, G. S. Cumming, and B. F. N. Erasmus, "Getting the most out of atlas data," Diversity and Distributions, vol. 16, no. 3, pp. 363-375, 2010.

[17] E. H. Perring and S. M. Walters, Atlas of the British Flora, Botanical Society of the British Isles, T. Nelson, London, UK, 1962.

[18] P. T. Harding, "National species distribution surveys," Monitoring for Conservation and Ecology, pp. 133-154, 1991.

[19] North American Ornithological Atlas Committee, Handbook for Atlasing American Breeding Birds, Vermont Institute of Natural Science, Woodstock, Vt, USA, 1990.

[20] C. S. Robbins and E. A. T. Blom, Eds., Atlas of the Breeding Birds of Maryland and the District of Columbia, University of Pittsburgh Press, Pittsburgh, Pa, USA, 1996.

[21] W. G. Ellison, Ed., Atlas of the Breeding Birds of Maryland and the District of Columbia, Johns Hopkins University Press, Baltimore, Md, USA, 2nd edition, 2010.

[22] New Jersey Endangered and Nongame Species Program, New Jersey's Herp Altas Project: Herp Atlas Volunteer Training Manual, New Jersey Department of Environmental Protection, NJ, USA, 2002.

[23] G. D. Therres, C. A. Davis, and C. W. Swarth, "Gridbased Herp Atlas using active searching: a pilot project," Final Report, Maryland Department of Natural Resources, Annapolis, Md, USA, 2011.

[24] D. H. Foley III and S. A. Smith, Comparison of two herpetofaunal inventory methods and an evaluation of their use in a volunteer-based statewide reptile and amphibian atlas project, 
Final Report, Maryland Department of Natural Resources, Wye Mills, Md, USA, 1999.

[25] M. L. Hunter Jr., J. Albright, and J. Arbuckle, Eds., The Amphibians and Reptiles of Maine, Maine Agricultural Experiment Station Bulletin 838, 1992.

[26] B. I. Crother, J. Boundy, F. T. Burbrink et al., Scientific and Standard English Names of Amphibians and Reptiles of North America North of Mexico, with Comments Regarding Confidence in Our Understanding, SSAR Herpetological Circular 37, 6th edition, 2008.

[27] R. Bonney, C. B. Cooper, J. Dickinson et al., "Citizen science: a developing tool for expanding science knowledge and scientific literacy," BioScience, vol. 59, no. 11, pp. 977-984, 2009.

[28] R. Gauza and D. Smith, Maryland Amphibian and Reptile Atlas (MARA) Training Handbook, Maryland Department of Natural Resources, Natural History Society of Maryland, 2010.

[29] J. B. Jensen, C. D. Camp, W. Gibbons, and M. J. Elliott, Eds., Amphibians and Reptiles of Georgia, University of Georgia Press, Athens, Ga, USA, 2008. 

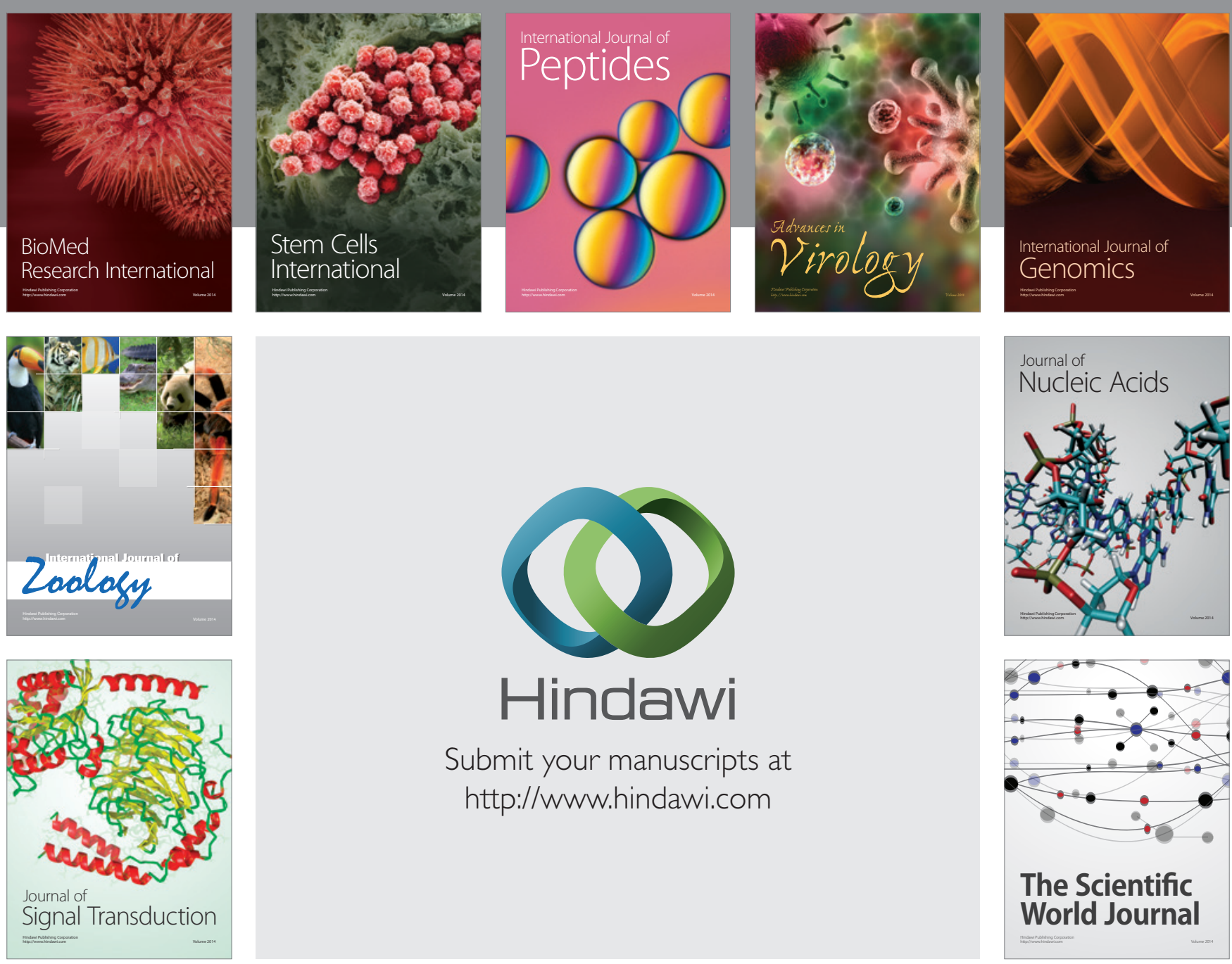

Submit your manuscripts at

http://www.hindawi.com
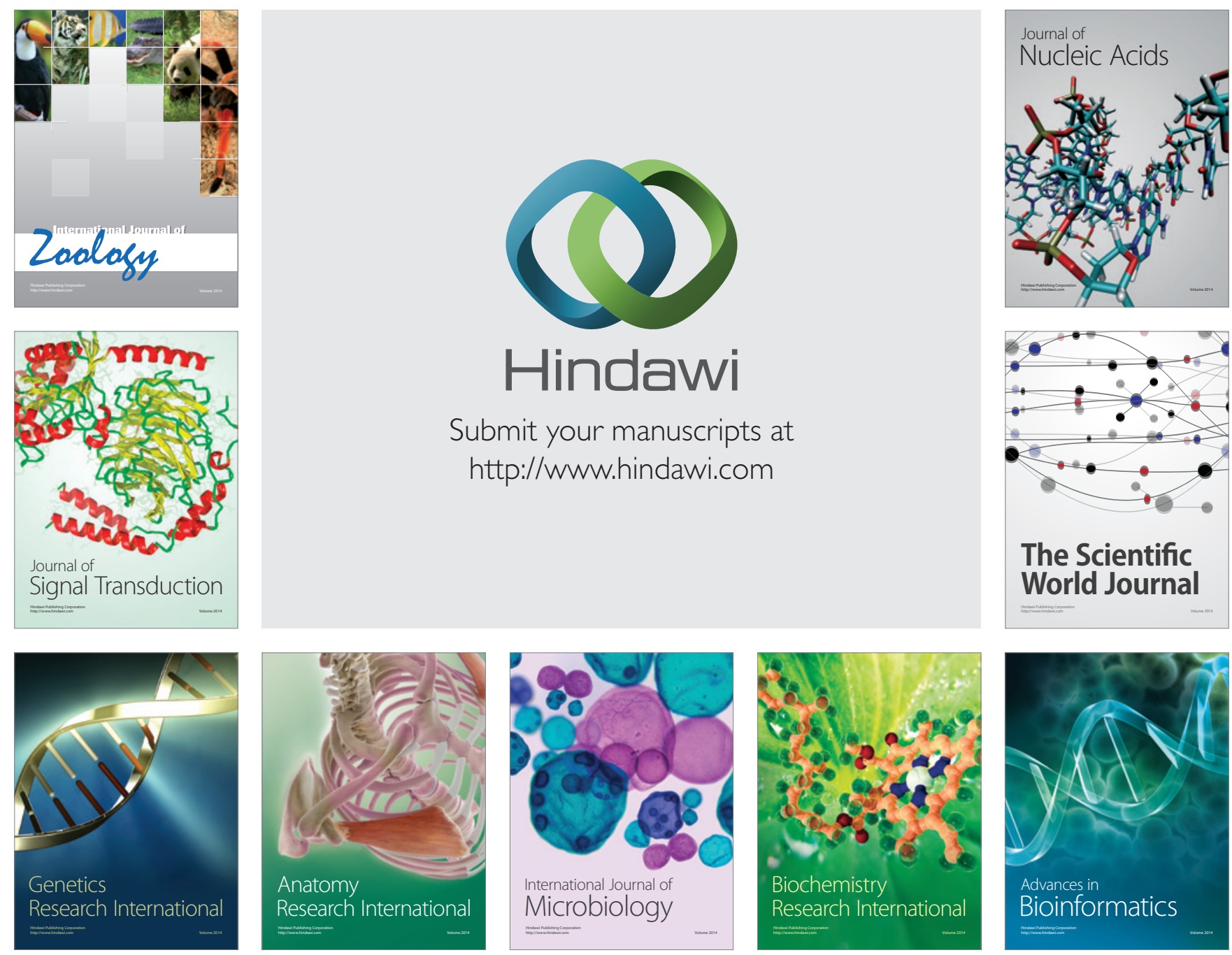

The Scientific World Journal
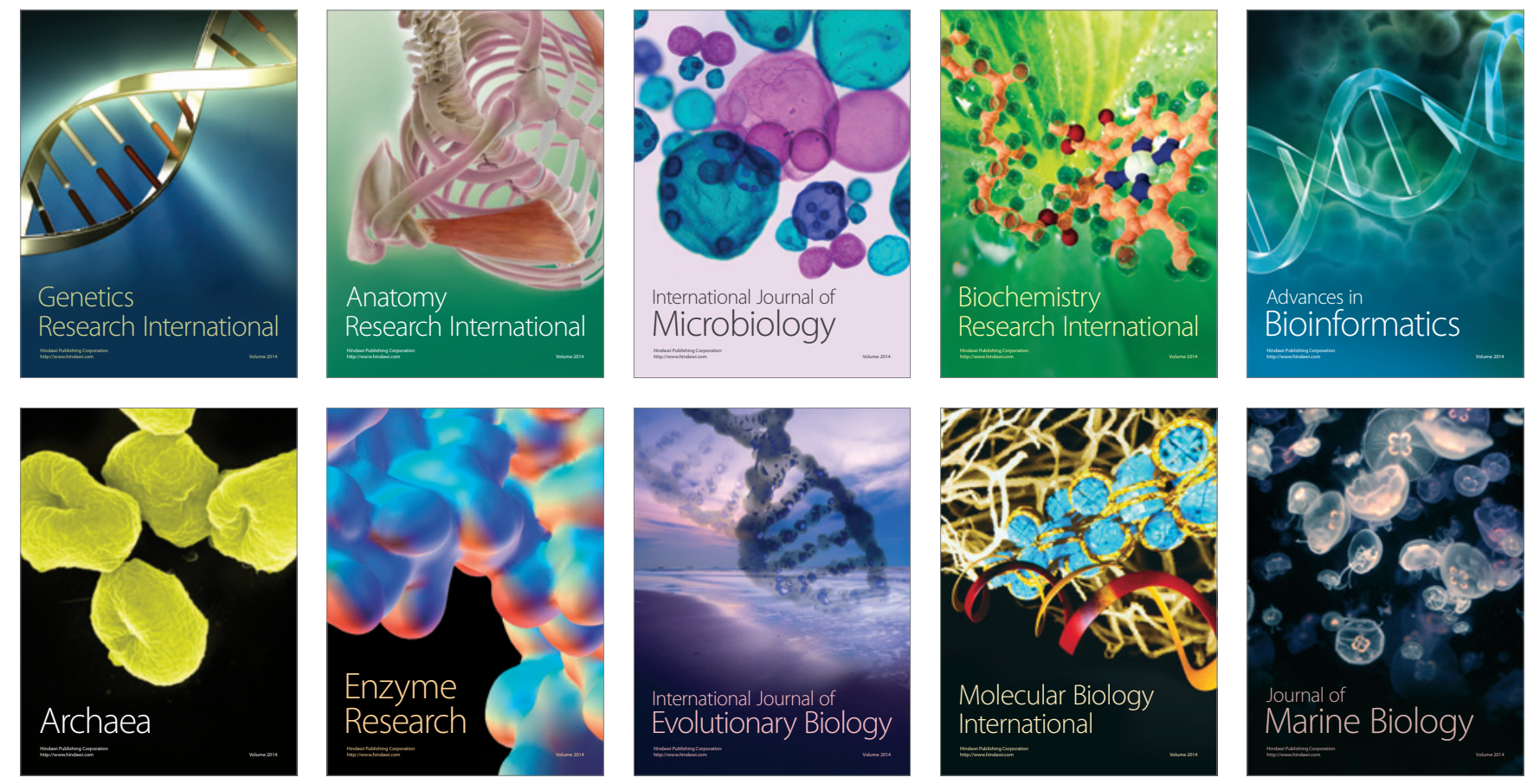